\title{
Corneal collagen crosslinking in the treatment of infectious keratitis
}

This article was published in the following Dove Press journal:

Clinical Ophthalmology

6 September 2011

Number of times this article has been viewed

\author{
Hamed Mofeez Anwar \\ Alaa M El-Danasoury \\ Ayman Nasr Hashem \\ Magrabi Eye Hospital, Jeddah, Saudi \\ Arabia
}

Purpose: To report the use of corneal collagen crosslinking in the treatment of infective keratitis not responding to antimicrobial therapy.

Methods: Two retrospective case reports of infective keratitis treated with corneal collagen crosslinking.

Results: In both cases, corneal collagen crosslinking caused a rapid resolution of the infective keratitis, leaving residual stromal scarring. Due to the density of scarring, one case required subsequent penetrating keratoplasty for visual rehabilitation.

Conclusion: Corneal collagen crosslinking is a promising new technique for the management of infective keratitis not responding to antimicrobial therapy. Further elucidation of its safety and role in management of infectious keratitis is needed by way of future studies.

Keywords: CCL, riboflavin, UVA

\section{Introduction}

Ulcerative keratitis is a sight-threatening condition, which requires skilled management and effective chemotherapy to preserve vision. If appropriate antimicrobial treatment is delayed, it is estimated that only $50 \%$ of eyes heal with good visual outcome. ${ }^{1}$

The treatment of corneal ulcers with topical antimicrobial agents has been confounded by the ability of microbes to develop resistance to the drugs used. There is therefore a need for an agent which provides complete, rapid antimicrobial activity with a minimum of toxicity.

Riboflavin and ultraviolet light (UV) collagen crosslinking of the cornea induces a change in properties of the collagen and has a stiffening effect on the corneal stroma, which stabilizes it and increases its resistance to enzymatic degradation., ${ }^{2,3}$

Although corneal collagen crosslinking was originally introduced as a treatment for corneal ectasia by Wollensak et $\mathrm{al}^{4,5}$ it has been used in the treatment of a variety of other conditions such as symptomatic Fuch's corneal dystrophy, ${ }^{6}$ pseudophakic bullous keratopathy, ${ }^{7}$ and more recently, infectious keratitis. ${ }^{8-11}$

These two case reports describe the authors' experience with corneal collagen crosslinking for the treatment of infectious keratitis.

\section{Case I}

A 30-year-old lady presented at Magrabi Eye Hospital as a referral from a local ophthalmologist with a 2-week history of pain, redness, and decreased vision in her right eye. The referring ophthalmologist had diagnosed her as having bacterial keratitis in her right eye. Culture and sensitivity results showed Staphylococcus aureus to be
Correspondence: Hamed Mofeez Anwar Magrabi Eye Hospital, PO Box 7344, Jeddah 2I462, Saudi Arabia Email hamidanwar@hotmail.com 
the causative microorganism. Treatment had already been initiated with intensive topical fortified antibiotic therapy with hourly fortified cefuroxime drops (5\%) together with hourly fortified gentamicin drops $(1.5 \%)$. However, in spite of initial sensitivities showing susceptibility to these antibiotics, the infection had progressed.

Best-corrected visual acuities (BCVAs) were finger counting at 1 meter in the right eye and 20/20 in the left eye. Ocular examination showed an elliptical, central area of corneal infiltration, $4 \mathrm{~mm} \times 2 \mathrm{~mm}$ in diameter (Figure 1A). A moderate anterior chamber reaction of more than two cells was seen, and no hypopyon. The conjunctiva was congested, but no purulent discharge was seen.

Medications were stopped for 24 hours, after which corneal scraping was repeated to obtain material for Gram and Giemsa slides, together with culture and sensitivity plating. The fortified gentamicin $1.5 \%$ and cefuroxime 5\% drops were recommenced. However, gram stain and cultures yielded no result.

A week later, the corneal abscess appeared to have increased in size. The risks of progression and corneal perforation, if treatment continued with conservative management, were weighed against the possible benefits of decreasing the load of pathogen with UV irradiation were discussed with the patient, after which the decision was made to proceed with UVA-riboflavin collagen crosslinking.

Topical anesthesia was achieved using $0.4 \%$ benoxinate drops. Epithelium was not removed as there was already a large epithelial defect overlying the abscess. Riboflavin drops (Medio-Cross ${ }^{\circledR}$ riboflavin/dextran solution, $0.1 \%$ ) were instilled topically to the cornea for a period of 20-30 minutes at an interval of 2-3 minutes. The cornea was then illuminated

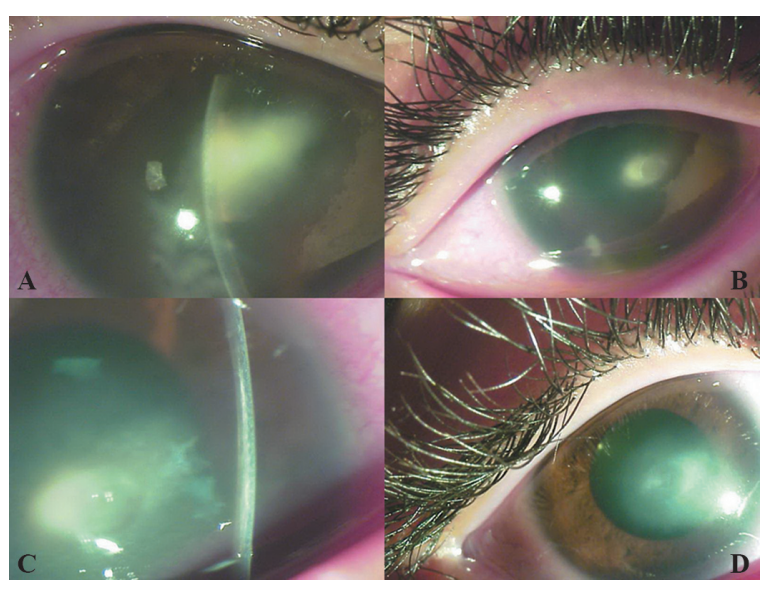

Figure I Appearance of case I (A) at initial presentation, (B) 2 weeks after crosslinking, (C) 2 weeks after crosslinking (note the stromal demarcation line due to crosslinking, adjacent to the abscess), and (D) 2 months after crosslinking. using a UVX lamp (PeschkeMeditrade GmbH, Huenenberg, Switzerland), UVA $365 \mathrm{~nm}$, with an irradiance of $3 \mathrm{~mW} / \mathrm{cm}^{2}$ and a total dose of $5.4 \mathrm{~J} / \mathrm{cm}^{2}$.

During the period of UV illumination, riboflavin was administered to the right eye at the same interval. Following this, treatment with gentamicin $1.5 \%$ and cefuroxime $5 \%$ drops was recommenced. Topical corticosteroids were not prescribed after the crosslinking procedure.

Follow-up examination at 1 week showed that the abscess had reduced in size to $2 \mathrm{~mm}$ in diameter and its margins were better defined. The epithelial defect overlying the abscess was also smaller. The patient also stated that she felt less pain. The medication was tapered at this point bringing the frequency of antibiotic drop instillation down to every 2 hours during the day.

Two weeks after crosslinking, the corneal abscess and epithelium had completely healed, with a residual scar remaining (Figure 1B). A demarcation line was clearly visible in the cornea adjacent to the corneal abscess (Figure 1C). BCVA improved to 20/100. Fortified antibiotic drops were discontinued and replaced by fluorometholone $0.1 \%$ /gentamicin 0.3\% (Infectoflam, Novartis Pharma AG, Basel, Switzerland) drops twice daily for 1 month. At 2 months, the BCVA was 20/40, the infection had completely resolved, but vision was impaired by a central corneal scar (Figure 1D).

\section{Case 2}

A 47-year-old laborer was referred to Magrabi Eye Hospital from another city after having been unsuccessfully treated for fungal keratitis at another hospital. He gave a vague history of some debris entering his eye while working a month back. After corneal scraping for Gram staining, Giemsa staining, and culture plating, he had initially been placed on hourly ciprofloxacin $0.3 \%$ eye drops. These had been changed to amphotericin $2 \mathrm{mg} / \mathrm{mL}$ eye drops after Sabouraud agar grew Aspergillus as a causative organism.

Visual acuities were hand motion in the right eye with accurate light projection and 20/20 in the left eye. Ocular examination showed a large corneal abscess measuring $9 \mathrm{~mm}$ horizontally by $7 \mathrm{~mm}$ vertically (Figure $2 \mathrm{~A}$ ). Temporally, the abscess was approaching the limbus. The bulbar and forniceal conjunctiva showed some patches of necrosis from prolonged amphotericin B treatment. Initial corneal scrapings yielded no hyphae, but a subsequent corneal biopsy confirmed the diagnosis of Aspergillus spp.

Considering the large size of the abscess and its proximity to the limbus, a therapeutic penetrating keratoplasty (PKP) was felt to be the most appropriate management. 


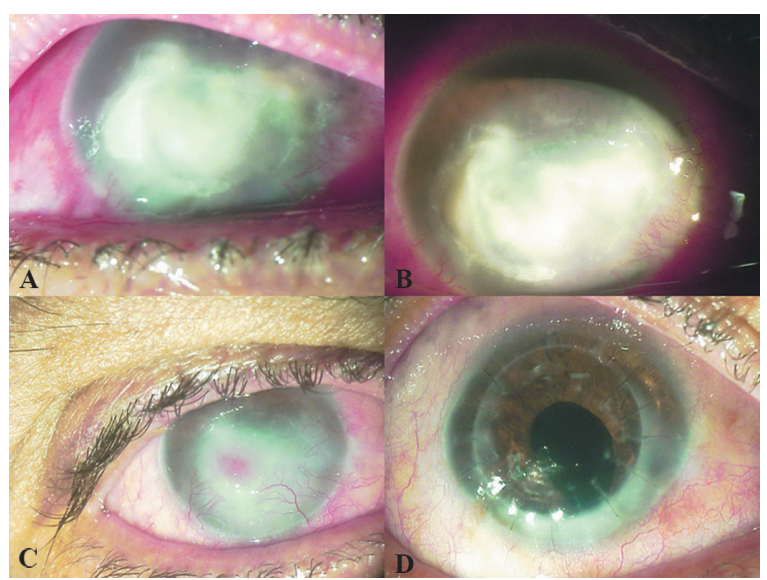

Figure 2 Appearance of case 2 (A) at initial presentation, (B) I week after crosslinking (note the cleaner margins and decreased infiltrate density of the abscess), (C) 2 months after crosslinking (infiltration has been replaced by scar tissue; note the presence of an intrastromal hemorrhage), and (D) after penetrating keratoplasty combined with cataract extraction.

However, given the poor outcomes of corneal grafting procedures in infectious keratitis, UVA-riboflavin crosslinking was performed in an attempt to decrease the fungal load in the corneal abscess. Treatment with hourly amphotericin $2 \mathrm{mg} / \mathrm{mL}$ eye drops was continued after the procedure. No topical corticosteroids were prescribed. One week after crosslinking, the corneal abscess appeared to have better-defined margins and less infiltration than before (Figure 2B). The epithelial defect appeared slightly smaller. Amphotericin drops were gradually tapered over the coming weeks.

Two months after crosslinking, the abscess had been replaced by scar tissue. The lesion diameter had decreased to $3 \mathrm{~mm}$. Superficial and deep stromal blood vessels were encroaching on the central cornea, causing an intra-abscess bleed (Figure 2C). By this point, the corneal epithelium had healed over the abscess. Amphotericin drops were discontinued.

Four months after crosslinking, penetrating keratoplasty combined with extracapsular cataract extraction and intraocular lens implantation was performed, uneventfully (Figure 2D). BCVA 6 months after the graft was 20/50, with a manifest refraction of $-2-4 \times 85$.

\section{Discussion}

The case reports presented here show that corneal collagen crosslinking has two possible roles in the treatment of infectious keratitis not responding to antibiotic therapy.

Firstly, the antimicrobial properties of UVA radiation destroy pathogenic microorganisms in the cornea, aiding resolution of the keratitis. Secondly, the crosslinking helps avoid an emergency penetrating keratoplasty with its associated high risks of graft rejection. The reported rates of graft rejection after therapeutic PKP range from $14.6 \%$ to $52 \%$ in various reported series. ${ }^{12-14}$ A $26 \%$ graft failure rate after rejection in therapeutic PKPs was reported by Hill. ${ }^{15}$

Tsugita et $\mathrm{l}^{16}$ showed that exposing riboflavin to UV light caused a deactivation of the ribonucleic acid (RNA) tobacco mosaic virus. Since then, research has been done to look into the possibility of using riboflavin as a photosensitizer to deactivate pathogens in plasma, platelet, and red cell products. ${ }^{17-19}$ The efficacy of UV light is limited only by its lack of penetration and its dependence on the distance from the light source. The cornea itself contains riboflavin already, but the concentration present is not enough to have antimicrobial effects in keratitis. The small amount of corneal riboflavin present may become depleted on exposure to sunlight. ${ }^{20}$

Martins et al showed that a combination of UVAriboflavin has antibacterial properties in vitro against microorganisms such as Pseudomonas aeruginosa, Staphylococcus aureus, Staphylococcus epidermidis, methicillin resistant Staphyloccus aureus, drug-resistant Streptococcus pneumoniae, and multidrug-resistant Pseudomonas aeruginosa. ${ }^{21}$ Pathogen inactivation occurs via the byproducts of riboflavin after UVA exposure. Nucleic acids are damaged by direct electron transfer, production of singlet oxygen, and generation of hydrogen peroxide with the formation of hydroxyl radicals. Pathogen deoxyribonucleic acid (DNA)/RNA may even be affected in the absence of oxygen. ${ }^{22,23}$

Spoerl et $\mathrm{al}^{24}$ showed that porcine corneas which underwent crosslinking were more resistant to the effects of pepsin, collagenase, and trypsin. Pepsin digested crosslinked eyes in 13 days and untreated eyes in 6 days. Collagenase digested treated corneas in 14 days and untreated eyes in 6 days. Trypsin digested treated corneas in 5 days and untreated corneas in 2 days. It is quite possible that part of the therapeutic effect of crosslinking in these cases was due to the decreased susceptibility of the corneal stroma to proteolytic enzymes produced by pathogenic bacteria.

The bactericidal and stromal strengthening properties of crosslinking make it a very attractive option for treating bacterial keratitis, as has been shown in case series by other authors. Al-Sabai describes a case of keratitis due to Pseudomonas spp. in which crosslinking helped induce corneal cicatrization. ${ }^{8}$ Iseli et al successfully crosslinked five patients with corneal melting due to infectious keratitis. Melting was arrested in all cases, with none requiring emergency keratoplasty. ${ }^{9}$ Makdoumi et al treated seven eyes of six patients with severe infectious keratitis, with crosslinking causing an arrest of 
melting and complete epithelialization in all cases, with a resolution of symptoms within 24 hours. ${ }^{10}$ Schnitzler reported that the treatment resulted in complete healing in two cases and delayed the need for surgery in another two cases. ${ }^{11}$ The findings of those case reports are mirrored in this current report, although the speed of resolution of these current cases was not as rapid as reported by Makdoumi et al.

In the bacterial infection, while fortified topical antibiotic therapy alone did not have the desired effect on the corneal abscess, the crosslinking led to a resolution of infection with an acceptable visual outcome, considering the location of the abscess.

The initial presentation of the fungal infection was clearly far more severe than that of the case of bacterial keratitis. The severity of the infection and the central location of the abscess caused scarring which limited the final visual acuity achieved. Penetrating keratoplasty was eventually required, but this was a more planned procedure in a less inflamed eye as compared with the therapeutic PKP which might have been performed in an acute setting.

In conclusion, UVA-riboflavin crosslinking could prove to be a valuable addition to our armamentarium for the treatment of keratitis not responding to antimicrobial therapy. In addition, it allows us to delay therapeutic PKP procedures to a later date when they can be performed in a more controlled manner with a possibly lower risk of subsequent graft failure. However, until more data is available crosslinking should only be considered in keratitis resistant to treatment.

\section{Disclosure}

The authors report no conflicts of interest in this work. This subject material has not been published elsewhere previously.

\section{References}

1. Jones DB. Decision-making in the management of microbial keratitis. Ophthalmol. 1981;88(8):814-820.

2. Wollensak G, Spoerl E, Seiler T. Stress-strain measurements of human and porcine corneas after riboflavin-ultraviolet-A-induced crosslinking. $J$ Cataract Refract Surg. 2003;29:1780-1785.

3. Spoerl E, Wollensak G, Seiler T. Increased resistance of crosslinked cornea against enzymatic digestion. Curr Eye Res. 2004;29:35-40.

Clinical Ophthalmology

\section{Publish your work in this journal}

Clinical Ophthalmology is an international, peer-reviewed journal covering all subspecialties within ophthalmology. Key topics include: Optometry; Visual science; Pharmacology and drug therapy in eye diseases; Basic Sciences; Primary and Secondary eye care; Patient Safety and Quality of Care Improvements. This journal is indexed on Submit your manuscript here: http://www.dovepress.com/clinical-ophthalmology-journal
4. Wollensak G, Spoerl E, Seiler T. Riboflavin/ultraviolet-A-induced collagen crosslinking for the treatment of keratoconus. Am J Ophthalmol. 2003;135(5):620-627.

5. Wollensak G, Sporl E, Seiler T. Treatment of keratoconus by collagen crosslinking (in German). Ophthalmologe. 2003;100(1):44-49.

6. Hafezi F, Dejica P, Majo F. Modified corneal collagen crosslinking reduces corneal oedema and diurnal visual fluctuations in Fuchs dystrophy. Br J Ophthalmol. 2010;94(5):660-661.

7. Ghanem RC, Santhiago MR, Berti TB, Thomaz S, Netto MV. Collagen crosslinking with riboflavin and ultraviolet-A in eyes with pseudophakic bullous keratopathy. J Cataract Refract Surg. 2010;36(2):273-276.

8. Al-Sabai N, Koppen C, Tassignon MJ. UVA/riboflavin crosslinking as treatment for corneal melting. Bull Soc Belge Ophtalmol. 2010;(315): $13-17$.

9. Iseli HP, Thiel MA, Hafezi F, et al. Ultraviolet A/riboflavin corneal cross-linking for infectious keratitis associated with corneal melts. Cornea. 2008;27(5):590-594.

10. Makdoumi K, Mortensen J, Crafoord S. Infectious keratitis treated with corneal crosslinking. Cornea. 2010;29(12):1353-1358.

11. Schnitzler E, Spörl E, Seiler T. Irradiation of cornea with ultraviolet light and riboflavin administration as a new treatment for erosive corneal processes, preliminary results in four patients. Klin Monbl Augenheilkd. 2000;217:190-193.

12. Xie L, Zhai H, Shi W. Penetrating keratoplasty for corneal perforations in fungal keratitis. Cornea. 2007;26(2):158-162.

13. Rao GN, Garg P, Sridhar MS. Penetrating keratoplasty in infectious keratitis. In: Brightbill FS, editor. Corneal Surgery: theory, technique and tissue. 3rd ed. St Louis: Mosby; 1999:518-525.

14. Foster CS, Duncan J. Penetrating keratoplasty for Herpes simplex keratitis. Am J Ophthalmol. 1981;92(3):336-343.

15. Hill JC. Use of penetrating keratoplasty in acute bacterial keratitis. Br J Ophthalmol. 1986;70(7):502-506.

16. Tsugita A, Okada Y, Uchara K. Photosensitized inactivation of ribonucleic acids in the presence of riboflavin. Biochim Biophys Acta. 1965; 103(2):360-363.

17. Goodrich RP. The use of riboflavin for inactivation of pathogens in blood products. Vox Sang. 2000;78(Suppl 2):211-215.

18. Samar BM, Goodrich RP. Viral inactivation in plasma using riboflavinbased technology. Transfusion. 2001;41(Suppl):88S.

19. McAteer MJ, Tay-Goodrich B, Doane S, et al. Photoinactivation of virus in packed red blood cell units using riboflavin and visible light. Transfusion. 2000;40(Suppl):99S.

20. Bessey OA, Lowry, OH. Factors influencing the riboflavin content of the cornea. J Biol Chem. 1944;155:635-646.

21. Martins SA, Combs JC, Noguera G, et al. Antimicrobial efficacy of riboflavin/UVA combination $(365 \mathrm{~nm})$ in vitro. Invest Ophthalmol Vis Sci. 2008;49(8):3402-3408.

22. Baier J, Maisch T, Maier M, Engel E, Landthaler M, Baumler W. Singlet oxygen generation by UV-A light exposure of endogenous photosensitizers. Biophys J. 2006;91(4):1452-1459.

23. Hiraku Y, Ito K, Hirakawa K, Kawanishi S. Photosensitized DNA damage and its protection via a novel mechanism. Photochem Photobiol. 2007;83(1):205-212.

24. Spoerl E, Wollensak G, Seiler T. Increased resistance of crosslinked cornea against enzymatic digestion. Curr Eye Res. 2004;29(1):35-40.
PubMed Central and CAS, and is the official journal of The Society of Clinical Ophthalmology (SCO). The manuscript management system is completely online and includes a very quick and fair peer-review system, which is all easy to use. Visit http://www.dovepress.com/ testimonials.php to read real quotes from published authors. 